\title{
Technology Access: Resources Wasted in Computer Laboratories
}

\author{
Kristian Kiili \\ Tampere University of Technology, Pori unit, Korkeakoulunkatu 10, Tampere, Finland, \\ kristian.kiili@tut.fi
}

\begin{abstract}
The technological infrastructure of Finnish schools varies a lot. In some schools there are computers for almost every pupil in the classroom. On the other hand there are also schools with only a few computers in the whole school. The purpose of this paper is to study how teachers from different schools and school levels utilize technological resources in their teaching. The hypothesis is that good technological infrastructure does not guarantee the use of technological devices in teaching. The data was gathered with an electronic questionnaire in Fall 2002, in order to investigate whether pupils used computers more when the computers were placed in the classroom. Likewise teachers' use of computers for demonstration increased when the computers were placed in the classroom. The number of computers in separate computer rooms did not increase the usage. Thus the most important thing to be considered when planning schools' computer infrastructure is the location of computers.
\end{abstract}

\section{INTRODUCTION}

According to the national strategy of the Ministry of Education in Finland, the task of the school is to give every pupil the basic skills of knowledge acquisition, communication and maintenance needed in information society and further studies (Alajääski, 2000). To reach this goal and guarantee high-quality technology education there must be a certain technological infrastructure in schools. Even if schools have a good technological infrastructure, education does not always fulfil the requirements of the Ministry of Education. There can be several reasons for low use of technological devices in schools. One reason could be teachers' level of mastery of technology that varies a lot. Teachers may have

The original version of this chapter was revised: The copyright line was incorrect. This has been corrected. The Erratum to this chapter is available at DOI: 10.1007/978-0-387-35701-0_35 
prejudices against technology and their skills in technology may be poor. Nonetheless there are also technologically skilful teachers who do not utilize their skills in teaching. The question is, why? Maybe these teachers do not see the value of technology in education or the technology in schools is difficult to access. The number of computers is not the only way to consider the infrastructure of schools.

\section{METHOD}

Survey research was conducted in Finland in Fall 2002. The 80 schools that took part in the survey were chosen in terms of judgement sampling. The electronic questionnaire was sent to 800 primary and high school teachers via e-mail. There were 12 questions in the questionnaire dealing with teachers' computing skills, work experience, ways of using computers in their profession, opinions about using computers in schools and schools' infrastructure. Before distribution the questionnaire was tested by two teachers and some modifications were made to it.

According to Kerlinger (1988), mail questionnaires have serious drawbacks unless they are used with other techniques. Return percentages are usually low and given responses cannot be checked. These same drawbacks are valid also in e-mail questionnaires. In this study the response rate was as low as $9.7 \%(\mathrm{~N}=78)$, although it took only five minutes to fill in the questionnaire. Because of the low response rate and small sample, valid statistical generalisations cannot be made. Although the sample is geographically comprehensive, it is not representative. The data gathering technique used, electronic questionnaire distributed via e-mail, is not appropriate for this study. It might be that the teachers who replied to the questionnaire are more familiar with computers than an average teacher in Finland because of the way the questionnaires were distributed. To gather more valid data the questionnaire should be distributed in paper format via mail to teachers. That would offer those teachers who cannot or will not use e-mail the possibility of answering. Some interviews should also be carried out.

Finally four groups were formed from teachers on the basis of the class level that they had been teaching.

- Lower primary school teachers (9-10 year old pupils, $n=14)$

- Middle primary school teachers (11-12 year old pupils, $n=22$ )

- Upper primary school teachers (13-14 year old pupils, $n=18)$

- High school teachers (15-16 year old pupils, $n=24)$

The data was analysed by descriptive tests and by calculating correlation matrices between variables formed from gathered data. 


\section{RESULTS}

First participants' computing skills were measured by defining which applications they could use. Teachers marked from the questionnaire those applications items that they could use satisfactorily. Naturally this is only a superficial description of teachers' skills. All teachers were familiar with word processing and e-mail. $97 \%$ of teachers could use the Internet. Approximately half of the teachers could use some spreadsheets, graphics programs and presentation programs. Only $26 \%$ were familiar with learning environments and $10 \%$ had used multimedia programs like Flash. On the basis of these results it seems that almost every teacher had good basic skills to organize computer-aided teaching.

According to teachers' estimates, pupils used computers in schools for approximately 67 minutes per week on average. Figure 1 shows that pupils of higher school levels used computers more than pupils of lower school levels. Lower primary school pupils used computers for about 35 minutes per week. High school pupils use computers for about 90 minutes. When the correlation between school levels and the time that pupils used computers in school was calculated, a significant relationship was found $(p=0.0012)$. There was no significant relationship found between the amount of teachers' work experience and the time that pupils used computers in school $(\mathrm{p}=0.1976)$.

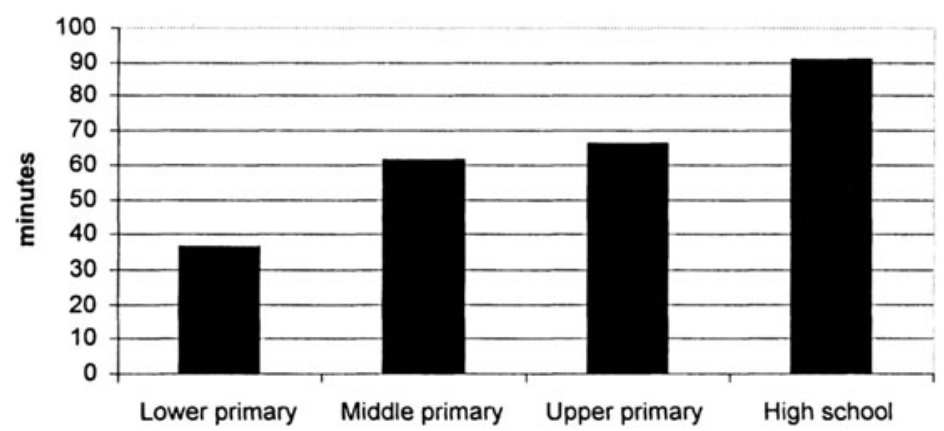

Figure 1. Pupils' average use of computers per week according to teachers' estimates

Pupils used computers more when computers were placed in classrooms than in separate computer laboratories. When the correlation between the time that pupils used computers and the number of computers in the classroom was calculated, a significant relationship was found $(p=0.00145)$. Surprisingly the number of computers in computer rooms did not increase the use of computers. When the correlation between the time that pupils used computers and the number of computers in computer rooms was calculated, no significant relationship was found $(\mathrm{p}=0.706)$. It seems that the location of 
computers is a more important factor than the number of computers in the school when evaluating the time pupils use computers. On the basis of these results computers should be placed into classrooms not in separate computer laboratories.

One way to use computers in teaching is demonstration. In this paper demonstration includes a wide range of ways to use computers in teaching, varying from simple PowerPoint slide shows to complex animations used to clarify abstract concepts. Figure 2 shows that teachers of higher school levels used computers for demonstration during lessons more than teachers of lower school levels.

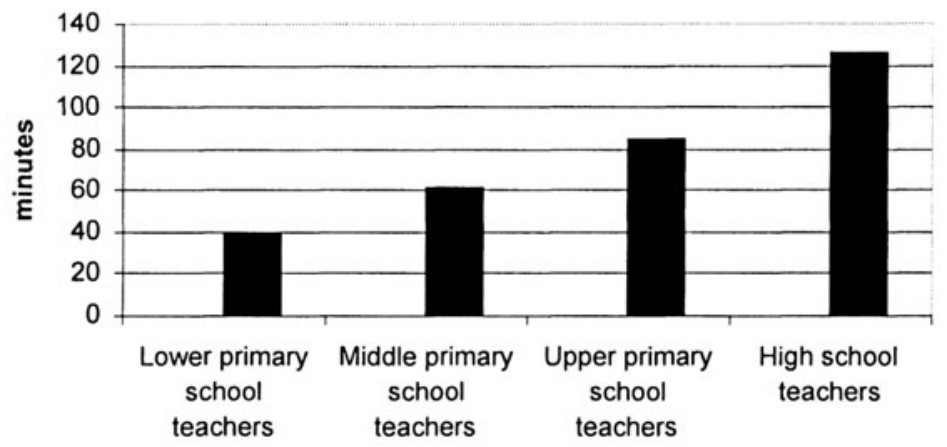

Figure 2. Teachers' average use of computers for illustration during lessons per week

High school teachers used computers for demonstration 126 minutes per week on average. The least use of computers for demonstration was by lower primary school teachers, only 39 minutes per week on average. When the correlation between teachers' use of computers for demonstration and school levels was calculated, a significant relationship was found $(p=0.00202)$. In addition when correlation between teachers' use of computers for demonstration and the number of computers in the classroom was calculated, a very significant relationship was found $(p=0.0000004)$. On the other hand there was no significant relationship found between teachers' use of computers for demonstration and the number of computers in computer laboratories $(\mathrm{p}=0.3929)$. It seems that computers in computer laboratories are not fully used. This also supports the idea that computers should be placed into classrooms.

Teachers use computers for approximately two hours per week to prepare lessons. Teachers of higher school levels use computers in preparing lessons more than teachers of lower levels $(p=0.0086)$. When the correlation between work experience and preparation time was calculated an almost significant relationship was found $(\mathrm{p}=0.0481)$. Inexperienced teachers used computers in preparing lessons less than experienced teachers. 


\section{DISCUSSION}

It seems that the location of computers is a very important factor in the accessibility of technology in schools. Pupils and teachers used computers in schools more when computers were placed in classrooms rather than in separate computer laboratories. One reason for lesser use of computer rooms might be the extra work that they cause to teachers. Teachers have to book the rooms a long time before the lessons and adjust their teaching to the availability of the laboratories. If there are only one or two laboratories in a school, situations can arise when several teachers would like to use the computers at the same time. When this kind of conflict happens often it may decrease the use of the laboratories. Another bad aspect of laboratories is that teachers usually use them for one hour at time. When computers are placed in the classrooms they can be used on impulse. Shorter periods of use are possible, and the use can be better integrated into other subjects. At least one computer should be in every classroom so that the teacher can use it for demonstration during lessons. School decision makers should sit down and reconsider the organization of school infrastructure.

\section{REFERENCES}

Alajääski, J. (2000). The Development of Mastery of Computer Teaching-related Topics and the Impact of Computer Teaching in an IT-based Teaching Environment as Assessed by the Teachers in the Teacher Training School in Rauma. Tampere: Tampere University of Technology Publications 287.

Kerlinger, F. N. (1988). Foundation of Behavioral Research. New York: Holt Rinehart \& Winston. 